\title{
Fragile sites are preferential targets for integrations of $M L V$ vectors in gene therapy
}

\author{
AC Bester, M Schwartz, M Schmidt, A Garrigue, S Hacein-Bey-Abina, M Cavazzana-Calvo, \\ $\mathrm{N}$ Ben-Porat, C Von Kalle, A Fischer and B Kerem
}

Gene Therapy (2007) 14, 282. doi:10.1038/sj.gt.3302904

Correction to: Gene Therapy (2006) 13, 1057-1059. doi:10.1038/sj.gt.3302752

Since the above publication the authors have noticed an error in the first DNA marker of FRA11E in Supplementary Table 1S. The correct table is shown below:

Table 1S Analyzed sequences from common fragile site regions and number of MLV integrations in each fragile region

\begin{tabular}{|c|c|c|c|c|c|c|}
\hline & Chromosomal position $^{a}$ & First DNA marker ${ }^{\mathrm{b}}$ & Last DNA marker ${ }^{\mathrm{b}}$ & Reference $^{\mathrm{e}}$ & $\mathrm{CD} 3+^{\mathrm{c}}$ & $\mathrm{HeLa}^{\mathrm{d}}$ \\
\hline FRA2G & chr2: $169,452,095-170,292,618$ & RH91148 & RH1293 & 5 & 1 & 1 \\
\hline FRA3B & chr3: 59,594,241- $64,182,258$ & D3S3577 & D3S1287 & 6 & & 1 \\
\hline FRA4F & chr4: $89,694,006-97,605,145$ & RH94252 & D4S2407 & 7 & 1 & 3 \\
\hline FRA6E & chr6: $160,551,547-163,760,142$ & RH92608 & RH63999 & 8 & 2 & \\
\hline FRA6F & Chr6: $106,922,988-112,526,158$ & SHGC-140029 & D6S1259 & 9,10 & 1 & 1 \\
\hline FRA7E & chr7: $79,882,815-84,580,600$ & swss4015 & SHGC-104456 & 11 & & 6 \\
\hline FRA7G & chr7: $109,809,464-116,030,383$ & RH122988 & D7S2863 & 12,13 & & 2 \\
\hline FRA7H & chr7: $129,368,585-130,393,035$ & A006N09 & D7S2531 & 2 & 2 & 1 \\
\hline FRA7I & chr7: $144,322,489-145,530,291$ & D7S1477 & D7S739 & 14 & & \\
\hline FRA8C & chr8: $124,267,550-128,310,523$ & D8S1160 & SHGC-130454 & 13 & & 2 \\
\hline FRA9E & chr9: $106,403,642-116,118,637$ & SHGC-106699 & RH62868 & 15 & 3 & 2 \\
\hline FRA11E & chr11: $31,953,729-33,948,551$ & D11S1964 & D11S4965 & This study & 5 & 2 \\
\hline FRA16D & chr16: $76,161,223-77,681,818$ & D16S3138 & D16S516 & 16,17 & & \\
\hline \multirow[t]{2}{*}{ FRAXB } & chrX: $6,827,880-7,285,010$ & DXS1130 & DXS1133 & 18 & & \\
\hline & & & & & 15 & 21 \\
\hline
\end{tabular}

aPositions are denoted according to the 2004 freeze of the UCSC human sequence assembly.

bDNA markers mapped to the ends of the analyzed sequence.

'MLV integrations in CD3+ cells of nine treated SCID-X1 patients.

${ }^{\mathrm{d}} \mathrm{MLV}$ integrations in HeLa cells, from Wu et al.19

eSupplementary reference list.

The authors would like to apologise for this error. 